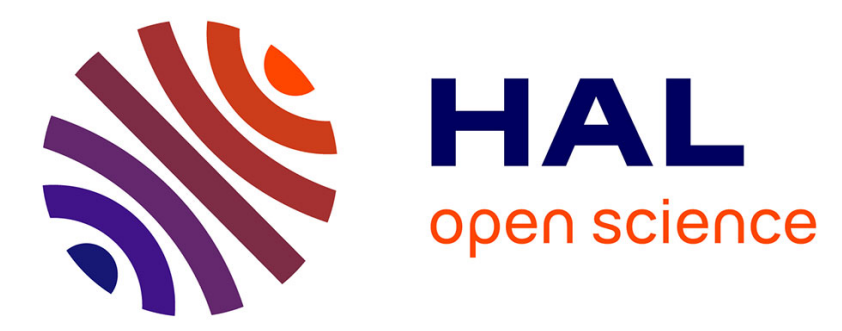

\title{
A scalable photomixing array for increased emitted power
}

\author{
A.J. Pascual, M. Ali, L.E. Garcia-Munoz, G. Carpintero, F. Van Dijk, D.
} Gonzalez-Ovejero, R. Sauleau

\section{To cite this version:}

A.J. Pascual, M. Ali, L.E. Garcia-Munoz, G. Carpintero, F. Van Dijk, et al.. A scalable photomixing array for increased emitted power. 2019 44th International Conference on Infrared, Millimeter, and Terahertz Waves (IRMMW-THz), Sep 2019, Paris, France. pp.1-2, 10.1109/IRMMWTHz.2019.8873999 . hal-02333627

\section{HAL Id: hal-02333627 \\ https://hal-univ-rennes1.archives-ouvertes.fr/hal-02333627}

Submitted on 25 Oct 2019

HAL is a multi-disciplinary open access archive for the deposit and dissemination of scientific research documents, whether they are published or not. The documents may come from teaching and research institutions in France or abroad, or from public or private research centers.
L'archive ouverte pluridisciplinaire HAL, est destinée au dépôt et à la diffusion de documents scientifiques de niveau recherche, publiés ou non, émanant des établissements d'enseignement et de recherche français ou étrangers, des laboratoires publics ou privés. 


\title{
A scalable photomixing array for increased emitted power
}

\author{
A.J. Pascual ${ }^{1}$, M. Ali ${ }^{2}$, L.E. García-Muñoz ${ }^{2}$, G. Carpintero ${ }^{2}$, F. van Dijk ${ }^{3}$, D. González-Ovejero ${ }^{1}$ and R. Sauleau \\ ${ }^{1}$ Univ Rennes, CNRS, IETR (Institut d’Electronique et de Télécommunications de Rennes) - UMR 6164, \\ F-35000, Rennes, France. \\ ${ }^{2}$ Universidad Carlos III de Madrid, Leganés 28911, Madrid, Spain \\ ${ }^{3}$ III-V Lab, Campus de Polytechnique, Avenue Augustin Fresnel 1, 91767 Palaiseau CEDEX, France
}

\begin{abstract}
The goal of this work is to increase the power emitted at E-band by a photomixing antenna array on PCB technology. The antenna architecture has been tailored to obtain a scalable design and a high radiation efficiency, while featuring a relative bandwidth larger than $10 \%$. Our first prototype, with a 3-dB gain bandwidth of $12 \mathrm{GHz}$ and one active photodiode, has been used in a wireless link. This preliminary demonstration has yielded a 2.15 $\mathrm{Gb} / \mathrm{s}$ error-free data rate transmission for a $25 \mathrm{~cm}$ distance.
\end{abstract}

\section{INTRODUCTION}

$\mathrm{M}$ Illimeter and sub-millimeter wave photonic-based transceivers feature promising characteristics to meet the increasing demand for high data rates in wireless communications. Their main advantages are a large bandwidth, seamless integration with deployed optical fiber networks, and re-use of well-established photonic technologies [1], [2]. These features have played a key role in the growth of photonicenabled technologies in the sub-Terahertz range. In addition, the integration of photodiodes with antenna arrays can offer attractive characteristics at the system level, such as photonicenabled 2D beam steering for applications where autoalignment and/or tracking are required. However, the main drawback of photonic generation at these wavelengths is the relatively low level of emitted power, typically ranging from a few hundreds of micro-watts to a few milliwatts. In this paper, we propose a proof of concept solution to increase the radiated power by employing two Uni-Travelling-Carrier Photodiodes (UTC-PD) integrated with an antenna array at E-band.

\section{ANTENNA DESIGN}

Fig. 1 shows the geometry of the proposed antenna, with center design frequency equal to $82 \mathrm{GHz}$. It consists of a 4-columns array, where each of the two UTC-PD feeds two columns. The array elements have been manufactured using PCB technology on a grounded Duroid 5880 substrate (thickness $127 \mu \mathrm{m}, \varepsilon_{\mathrm{r}}=2.2, \tan \delta=0.003$ ), suitable for high frequency applications. This planar design is scalable and advantageous in terms of integration with respect to classical sub-millimeter wave antennas, such as substrate lenses [3] and feed horns [4].

\section{A. Array Column}

Each column consists of a series fed stub array. In this particular case, a microstrip line is periodically loaded with groups of $\lambda / 4$ stubs that progressively radiate the input power. Each group includes 4 stubs: two towards the right and two towards the left. This configuration allows one to reduce the antenna size and to increase the radiation efficiency, while maintaining good radiation pattern performance. The 4 stubs are also equispaced to minimize the reflected power. The width of the stub controls the amount of power radiated, whereas the periodic spacing of the groups controls the pointing direction of
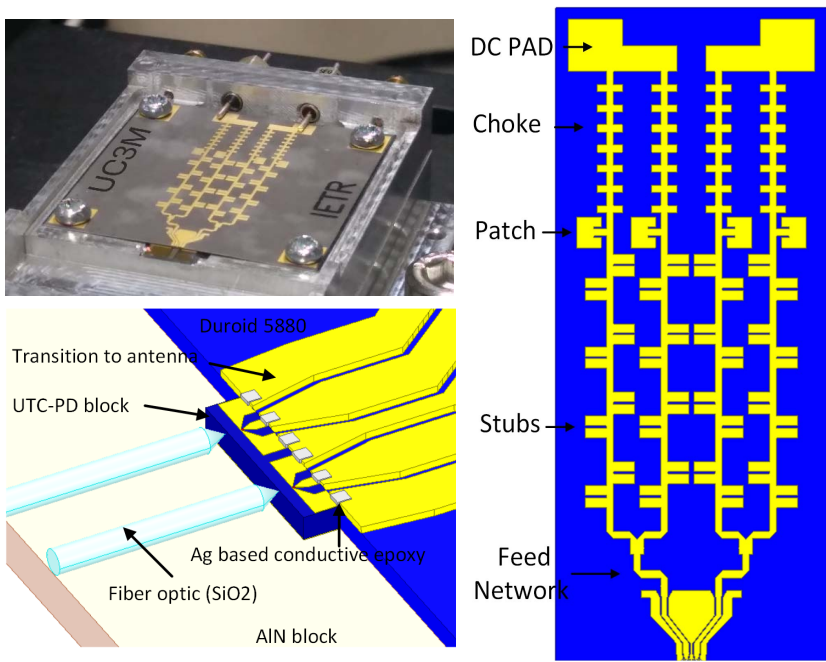

Fig. 1. Top left: Fabricated antenna prototype with housing and photodiode chip assembled. Bottom left: Detail of the feed structure of the antenna. Right: Front-view of the designed antenna layout.

the radiated beam. Although a similar configuration can be found in [5], here, it has been modified to obtain a compact design and to yield low $S_{11}$ values at the frequency of broadside emission. We have selected broadside-directed emission at the central frequency to minimize the beam squint with frequency, which is a desirable characteristic to test the system in a wireless communication link. However, off-broadside designs can be accomplished by changing the periodicity of the 4-stubs groups for applications such as imaging or radar, where scanning a wide area is usually an attractive feature.

Finally, the loaded microstrip line is terminated with a patch that truncates the stub array and radiates the remaining power. In addition, after the patch, an RF choke is placed to isolate the antenna from the pads used to bias and monitor the current of the photodiodes. The choke features an RF isolation better than $40 \mathrm{~dB}$ for the whole operating frequency range of the array.

The above-described column is then used to obtain the final planar array comprised of 4 columns. First, the column is duplicated to get a $2 \times 1$ array. Second, this $2 \times 1$ array is mirrored. Each $2 \times 1$ array is then excited by a photodiode in phase opposition, which leads to a significant reduction of the cross-polarization levels. The final structure consists of an approximately square array that produces nearly symmetrical patterns with a directivity between $18.5-20.0 \mathrm{~dB}$, side-lobe level $<-9 \mathrm{~dB}$ and $\mathrm{FWHM}<13^{\circ}$ in the $77-86 \mathrm{GHz}$ frequency range (see top of Fig. 2).

\section{B. Photodiode Excitation and Feed network}

The available chip contains two UTC photodiodes with a $500-\mu \mathrm{m}$ pitch integrated with a $50-\mathrm{Ohm}$ grounded coplanar waveguide (G-CPW) on InP. The photodiodes are mounted on an AlN block for mechanical support, handling and heat 
dissipation. Each photodiode is optically fed by a lensed fiber as shown in the bottom left-hand side of Fig. 1. The measured UTC-PD responsitivity is $0.17 \mathrm{~mA} / \mathrm{mW}$ when illuminated with a $4 \mu \mathrm{m}$ spot-size diameter fiber. The $3 \mathrm{~dB}$ electrical bandwidth of the photodiodes is $110 \mathrm{GHz}$ [6].

On the other hand, the antenna feed network comprises a tapered transition (see the bottom left in Fig. 1) to adapt the different widths of the $50 \mathrm{Ohm}$ G-CPW lines on the InP and the Duroid 5880 substrates. After this transition it follows a section in which the two G-CPW separate to conform to the columns separation, a transition to microstrip line, and a symmetric corporate feed network. The transition and the feed network have been optimized to minimize the reflection coefficient, cross-talk between photodiodes and the radiation losses that could degrade the patterns. The S-parameters simulation results are shown in Fig. 2.

\section{ANTENNA ASSEMBLY}

The first assembly step is the pick and place of the UTC-PDs chip on an AIN block. Next, the AIN block and the PCB that includes the antenna are glued to the housing (metal block in the top left of Fig. 1). The AIN block is placed parallel to the PCB in such a way that the G-CPW of the chip is aligned with and at the same height as the PCB. Finally, the UTC-PD is bonded to the PCB using a silver-based conductive epoxy. This approach results in a thicker wire compared to wire bonding, thus reducing the resistive losses and the inductance of the wire, which leads to a better electrical connection. Moreover, as pointed out in [7], the use of epoxy allows one to have the photodiodes and the antenna structure on different substrates. This is an interesting feature, since it allows one to envisage the integration of mm-wave amplifiers after the UTC-PD to increase the emitted power.

\section{PRELIMINARY MEASUREMENTS}

Power measurements of the fabricated prototype (see the top left of Fig. 1) with a single UTC-PD illuminated have shown a $12 \mathrm{GHz}$ (from 73 to $85 \mathrm{GHz}$ ) 3-dB bandwidth of emitted power. The maximum output power was $120 \mu \mathrm{W}$ for $45 \mathrm{~mW}$ input optical power and a $-2.5 \mathrm{~V}$ bias voltage $(9.8 \mathrm{~mA}$ photocurrent). Finally, a preliminary test of our prototype in a wireless communication link has yielded a $2.15 \mathrm{~Gb} / \mathrm{s}$ error-free data rate at $25 \mathrm{~cm}$ distance, (7.0 mA photocurrent) using On-Off Keying modulation format and direct detection with a Schottky Barrier Diode (SBD). Fig. 3 shows the obtained eye-diagram.
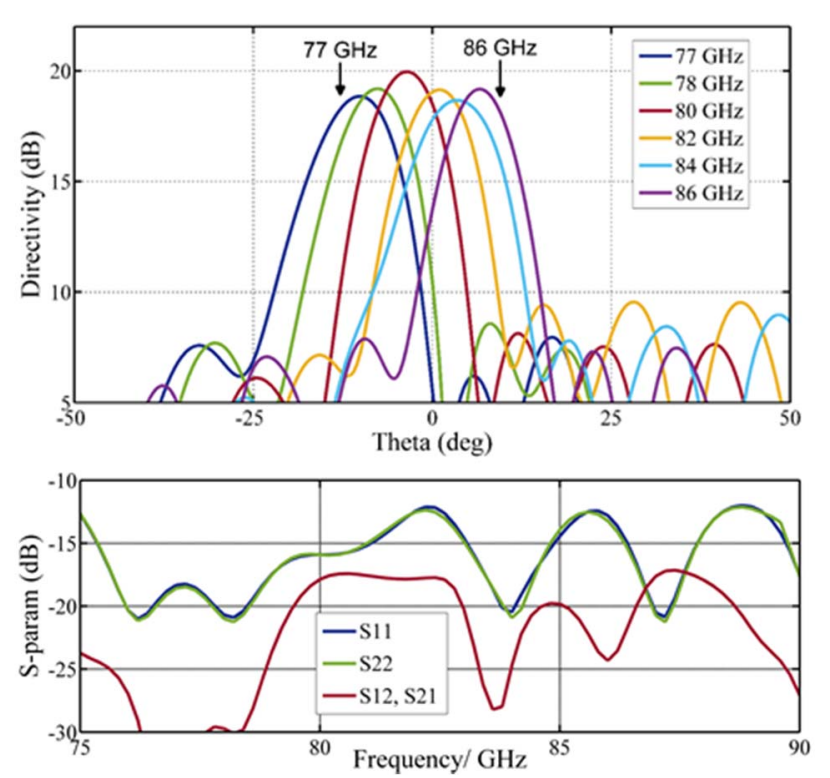

Fig. 2. Top: directivity patterns for different frequenies in H-plane (parallel to the columns). Bottom: magnitude of the reflection coefficients $\left(S_{11}, S_{22}\right)$ and cross-talk $\left(S_{12}, S_{21}\right)$ for the simulated structure, inlcudying the PCB, photodiode chip, AIN block and lensed fibers.

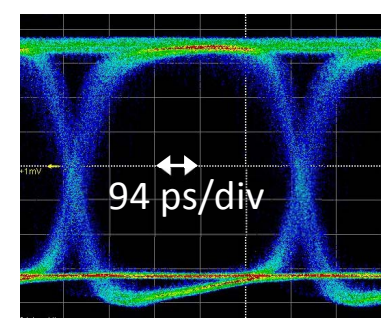

Fig. 3. Eye diagram at the SBD output for the $2.15 \mathrm{Gbps}$ error-free transmission experiment.

\section{SUMMARY}

This abstract presents an antenna concept for a photonic transmitter on PCB technology compatible with arrays of photomixers. Although measurements are ongoing, initial tests in a wireless communications link have proven the validity of the prototype. We expect to increase the data rate of the link and the emitted power when both photodiodes are active.

\section{REFERENCES}

[1] T. Nagatsuma, "Breakthroughs in photonics 2013: THz communications based on photonics," IEEE Photon. J., vol. 6, no. 2, pp. 1-5, 2014.

[2] T. Nagatsuma, et al., "Millimeter-wave and Teraherz-wave applications enabled by photonics," IEEE J. Quantum Elec., vol. 52, no. 1, 2016.

[3] E. García-Munoz et al., "Principles of emission of THz waves," in Semiconductor TeraHertz technology: Devices and systems at room temperature operation, G. Carpintero, E. García-Munoz, H. Hartnagel, S. Preu, A. Raisanen, Eds. John Wiley \& Sons, Chichester, UK, 2015.

[4] G. Chattopadhyay et al., "Terahertz antennas and feeds," in Aperture Antennas for Millimeter and Sub-Millimeter Wave Applications, A. Boriskin, R. Sauleau, Eds. Springer, 2017.

[5] J. R. James and P. S. Hall, "Microstrip antennas and arrays. Part 2: New array-design technique," IEE J. Microw., Optics and Acoust., vol. 1, no. 5, 1977. pp. 175-181.

[6] E. Rouvalis, et al., "High-speed photodiodes for InP-based photonic integrated circuits," Opt. Express, vol.20, no. 8, 2012. pp. 9172-9177.

[7] M. Ali, L. E. G. Muñoz and G. Carpintero, "E-band photonic transmitter with tapered slot antenna for RoF applications," 2017 Int. Topical Meeting on Microw. Photon. (MWP), Beijing, China, 2017, pp. 1-4. 